\title{
Wear and corrosion interaction of AISI D2 in an acidic environment
}

\author{
Tania Garcia' ${ }^{1}$, Andreas Zeinert ${ }^{1}$, Stephen Muhl ${ }^{2}$, Michaël Lejeune ${ }^{1}$ \\ 1Université de Picardie Jules Verne. 33 rue Saint Leu, Amiens, France,80000 \\ ${ }^{2}$ Instituto de Investigaciones en Materiales, Universidad Nacional Autónoma de México. Circuito Exterior S/N, Circuito \\ de la Investigación Científica, Ciudad Universitaria, Ciudad de México, México, 04510. \\ Corresponding author: Tania Garcia (tania.garcia@etud.u-picardie.fr))
}

\begin{abstract}
The tribological, electrochemical and tribo-electrochemical behavior of bare AISI D2 was studied. The tribological aspects were tested by pin on disc with an aluminum oxide ball as counter body, the electrochemical tests were performed in an aqueous solution of citric acid and the tribo-electrochemical evaluation was through a combination of both tests. AISI D2 steel presented abrasive wear in dry and wet conditions, such type of wear occurred due to stick-slip motion, moreover, in wet conditions the alloy corroded at corrosion current values around $10^{-6} \mathrm{~A} / \mathrm{cm}^{2}$. The damage produced over the wear track was larger under wet conditions than for the dry conditions.
\end{abstract}

Keywords: wear evaluation, corrosion, AISI D2

\section{Introduction}

In the tool steel classification one can find alloys with high carbon (up to $2.25 \%$ ) and high chromium (12\%) content. Such steels are classified by the American Iron and Steel Institute (AISI) in the D group, and the AISI D2 steel is widely used because it has many desirable properties, such as high wear resistance, high compressive strength, and good resistance to temper softening. Popular applications for the AISI D2 include cold drawing punches, shear blades, burnishing rolls, master tools, and gauges, slitting cutters, thread rolling and wire dies, chucks and rollers for seaming machines etc. [1-4]

Regardless of having good mechanical properties, the lifetime of pieces and accessories fabricated with AISI D2 steel can be affected by the work conditions in industrial processes. For example, parts for the seaming of cans in the canned food industry are often manufactured from AISI D2 steel, and during this process the liquid and vapor from the products being canned can come into contact with the steel $[5,6]$. This environment can negatively impact the performance of the parts and reduce their lifetime, and in general, such negative impact occurs as a result of severe corrosion. The composition of the solutions used for canned food varies from product to product, but citric acid is one of the most common compounds used. Thanks to its flavor and $\mathrm{pH}$ it is frequently used as an additive in beverages, jams, canned vegetables, fruits, etc., and when used to prevent bacterial growth the recommended $\mathrm{pH}$ level is 4 [7-10].

Regardless its extensive use, there are very few reports of wear and corrosion behavior of AISI D2 steel in presence of the common electrolytes found in food industry [11,12]. This work intents to be a preliminary guide upon the inter- action of wear and corrosion of tool steels in contact with common environments in the food processing industry.

\section{Material and methods}

\subsection{Materials}

Commercial grade AISI D2 steel discs of $3 \mathrm{~mm}$ of thickness were cut from a $3.0 \mathrm{~cm}$ diameter bar from "Weber Metaux". The reported composition for this alloy is $11-13 \mathrm{wt} \%$ Cr, 1.4-1.6 wt\% C, 0.7-1.2 wt\% Mo and 0.5-1.1 wt\% V. The crystalline structure of the samples was evaluated by X-ray diffraction (XRD) using $\mathrm{Cu} \mathrm{Ka}$ radiation in a Rigaku Ultima IV diffractometer. The resulting diffractogram is shown in Figure 1. The spectrum corresponds to that of an a iron phase in a cubic crystalline structure, typical for the cementite phase of steel. Such phase is commonly found on steels with high carbon content.

\subsection{Methods}

\subsubsection{Electrochemical tests}

Each sample was polished using a Buehler-MetaServ 250 at $15 \mathrm{~N}$ of load and $300 \mathrm{rpm}$ with different SiC abrasive papers of 600 to 1200, subsequently each sample was polished to a mirror finish using a cloth and a suspension of $0.1 \mu \mathrm{m} \mathrm{Al}{ }_{2} \mathrm{O}_{3}$ resulting in a surface roughness of $112 \pm 33$ nm. After polishing, each sample was rinsed with distilled water, cleaned with acetone (Fisher chemicals, general purpose grade) and finally with isopropanol (Sigma-Aldrich $\geq$ 99.7\%) for 10 min using an Elma ultrasonic bath. Each sample was dried with compressed air.

The electrochemical tests were performed using a Palm- 


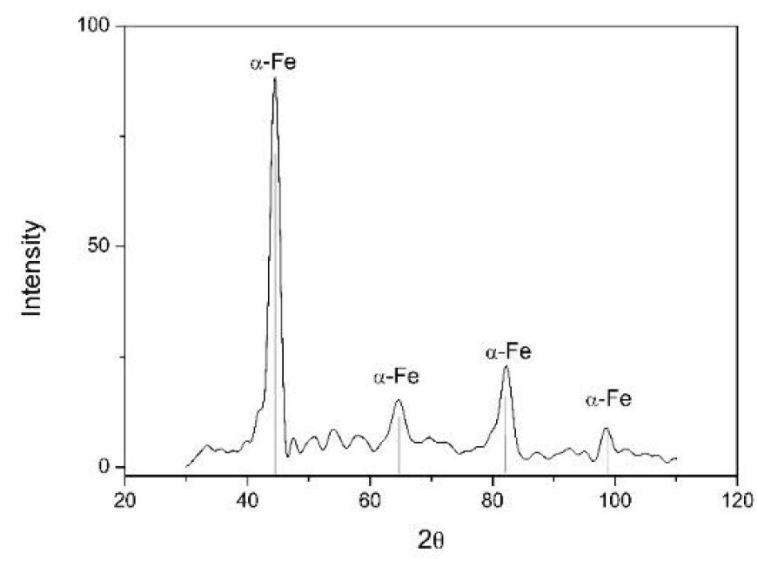

Figure 1 XRD pattern of the AISI D2 steel.

Sens 4 potentiostat. All measurements were performed with a three-electrode arrangement and a silver/silver chloride $(\mathrm{Ag} / \mathrm{AgCl})$ electrode as the reference, a platinum grid as the counter electrode and the steel disc as the working electrode. A $10^{-4} \mathrm{M}$ aqueous solution of citric acid (NortemBio/ food grade) was used as the electrolyte. The temporal evolution of the open circuit potential was measured for five hours to give a stable open circuit potential (OCP) measurement. Once the stable OCP was attained, either a linear polarization or an electrochemical impedance spectroscopy test was performed.

The linear polarization curves were obtained in a potential window from $-0.25 \mathrm{~V}$ vs. OCP to $-1.0 \mathrm{~V}$ vs. OCP at a scanning rate of $1.0 \mathrm{mV} / \mathrm{s}$. The polarization resistance $\left(R_{p}\right)$ was estimated using the Tafel extrapolation method with the Stern-Geary equation as follows:

$$
R_{p}=\frac{\beta_{a} \cdot \beta_{c}}{2.3039\left(\beta_{a}+\beta_{c}\right)} \cdot \frac{1}{i_{c o r r}}
$$
plots.

where $\beta_{a}, \beta_{c}$ are the slopes of anodic and cathodic Tafel

The electrochemical impedance spectroscopy measurements were performed using a $10.0 \mathrm{mV}$ perturbation in a frequency range of $10^{4}$ to $10^{-2} \mathrm{~Hz}$, and five measurements were made for each decade of frequency. The data were simulated using the equivalent circuit method, making use of the $\mathrm{Z}$ circuit fitting tool in the PS Trace 5.8 software. The Levernberg-Marquarat algorithm was used for all the measurements.

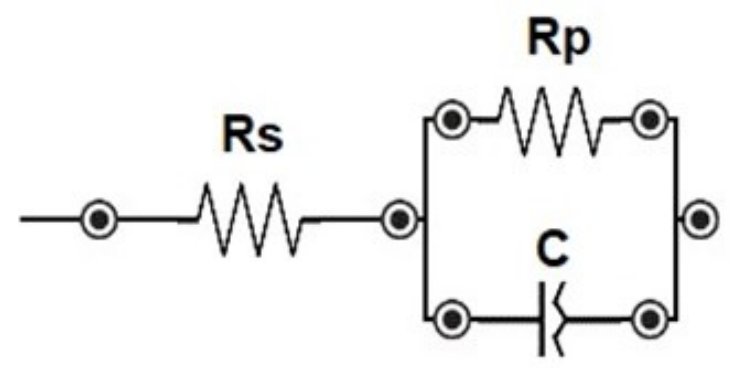

Figure 3 Equivalent circuit for the EIS response of AISI D2 in the citric acid $10^{-4} \mathrm{M}$ solution.

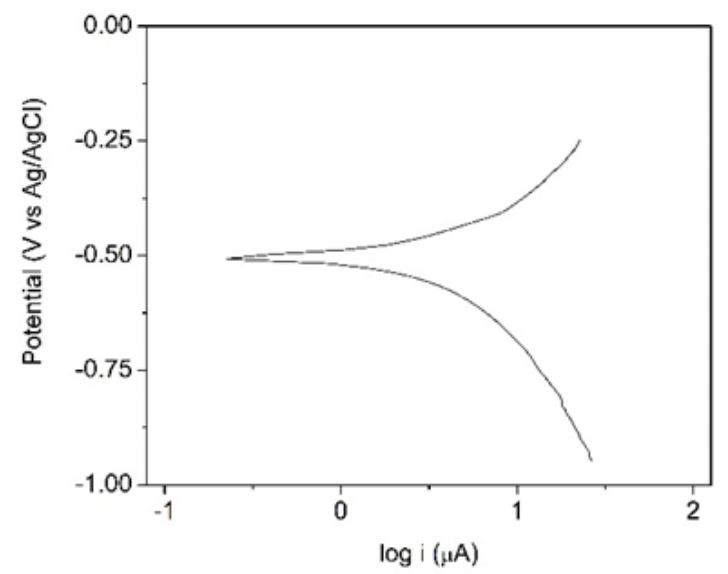

Figure 2 Linear polarization plot for AISI D2 in contact with a $10^{-4} \mathrm{M}$ citric acid aqueous solution.

\subsubsection{Tribological test}

The Pin on Disc measurements were performed using a Bruker UTM-Tribolab system using loads of $0.5 \mathrm{~N}$ (contact area $2.0 \times 10^{-9} \mathrm{~m}^{2}$ ) and $1.5 \mathrm{~N}$ (contact area $4.2 \times 10^{-9} \mathrm{~m}^{2}$ ). Aluminum oxide balls of $12 \mathrm{~mm}$ diameter and grade 20 , from Redhill Materials, were used as the counter body. The angular speed was $0.02 \mathrm{~m} / \mathrm{s}$ for a total measurement length of $72 \mathrm{~m}$. The tests were performed under 'dry conditions' (room temperature and relative humidity) and wet conditions (in contact with the $10^{-4} \mathrm{M}$ aqueous solution of citric acid). For the wet conditions, the samples were exposed to the citric acid solution for one hour before the pin on disc tests were started, to assure that the corrosion was in the steady state regime before the tribological testing.

To estimate the wear volume, mapping profilometries were carried out using a Dektak XT contact profilometer from Bruker, with a tip of $2 \mu \mathrm{m}$ curvature and a $3 \mathrm{mg}$ of applied force. The total analyzed area was a square of 7 $\mathrm{mm}$ with $15 \mu \mathrm{m}$ separation between every single profilometry scan. The obtained surface 3D map was analyzed with the software Visio 64 using the volume analysis filter ap-

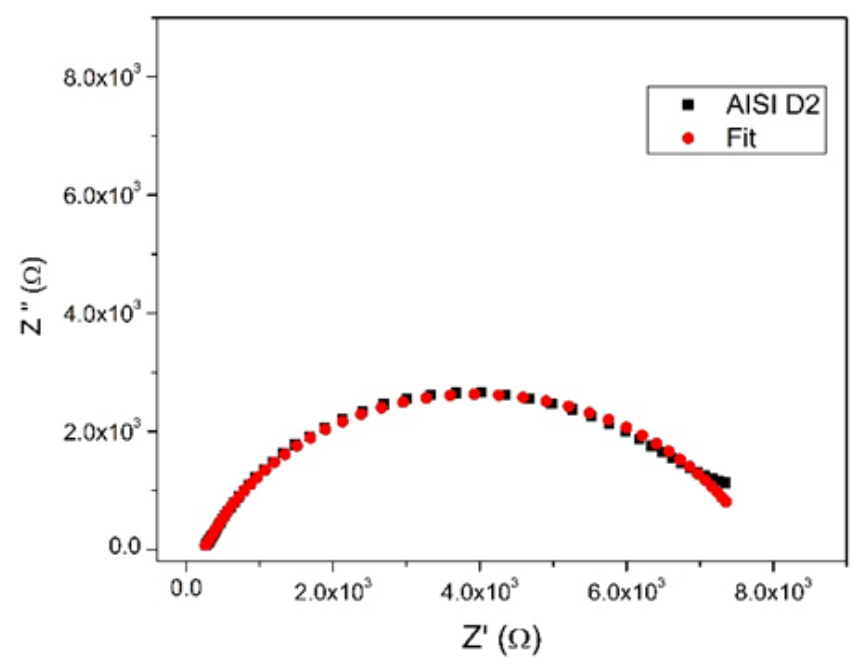

Figure 4 Nyquist diagram for the EIS of AISI D2 steel in contact with the citric acid $10^{-4} \mathrm{M}$ solution. 

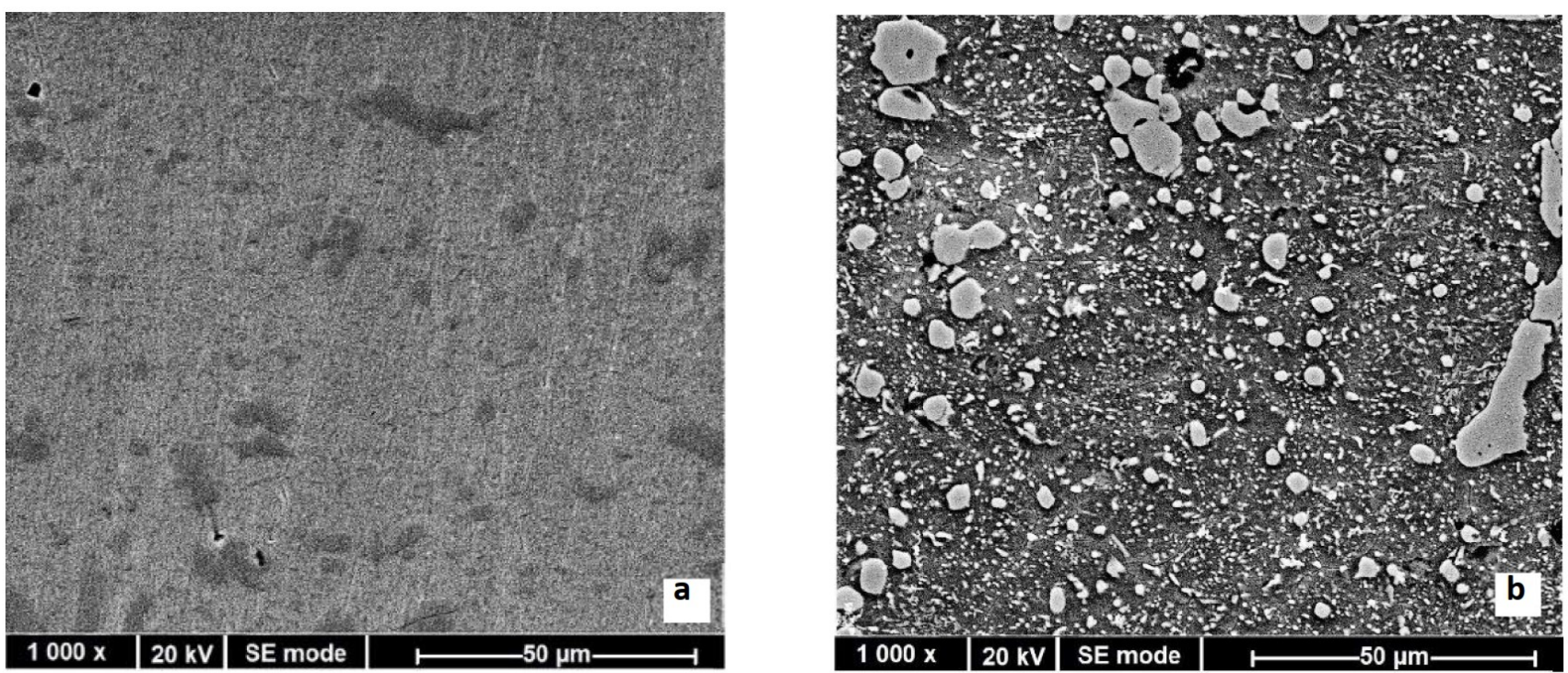

Figure 5 SEM image of the AISI D2 steel polished surface(a) and after being in exposed with the citric acid $10^{-4} \mathrm{M}$ solution (b).

plied to the wear track region.

Images of the material wear track were taken by scanning electronic microscopy, using a Quanta 200FEG microscope with a microanalyzer X INCA Oxford type SDD 80 $\mathrm{mm}^{2}$. For the steel samples, the images were obtained under high vacuum at $20 \mathrm{KeV}$ while for the counter bodies, the images were obtained at low vacuum and energies of about $10 \mathrm{KeV}$. While the EDS analysis was performed at high vacuum and $10 \mathrm{KeV}$ for both types of samples.

\section{Results and discussion}

\subsection{Linear polarization}

After a steady value of the OCP was obtained, plots of the potential (E) vs. the current logarithm (log i) were recorded. Figure 2 shows an example of such linear polarization curve, where it was possible to identify the cathodic and the anodic branches. A Tafel extrapolation of the curves was used to determine the corrosion potential and the corrosion current. The obtained corrosion potential was $0.5 \pm 0.05 \mathrm{~V}$ vs $\mathrm{Ag} / \mathrm{AgCl}$ which was consistent with the OCP. The corrosion current $\left(\mathrm{i}_{\text {corr }}\right)$ was $1.3 \times 10^{-6} \pm 1.2 \times 10^{-7} \mathrm{~A} /$ $\mathrm{cm}^{2}$ with $\beta_{a}=0.122 \mathrm{~V}$ and $\beta_{c}=0.018 \mathrm{~V}$. The $\beta$ values were used to calculate the polarization resistance, applying the second Stern and Geary relation (eq. 1) and gave a corrosion resistance of $19.3 \pm 0.8 \mathrm{k} \Omega \mathrm{cm}^{2}$.

\subsection{Electrochemical impedance spectroscopy}

An example of a typical Nyquist diagram and its fit are presented in Figure 3. The diagrams show one semicircle, hence one time constant, that has been shifted from the origin. Such behavior is commonly found during corrosion processes and can be described by the equivalent circuit shown in Figure 4. The proposed equivalent circuit consist of a resistance $R_{s}$ and a RC parallel circuit. $R_{s}$, which represents the ohmic resistance of the solution between the working and the reference electrodes. $R_{p}$ corresponds to

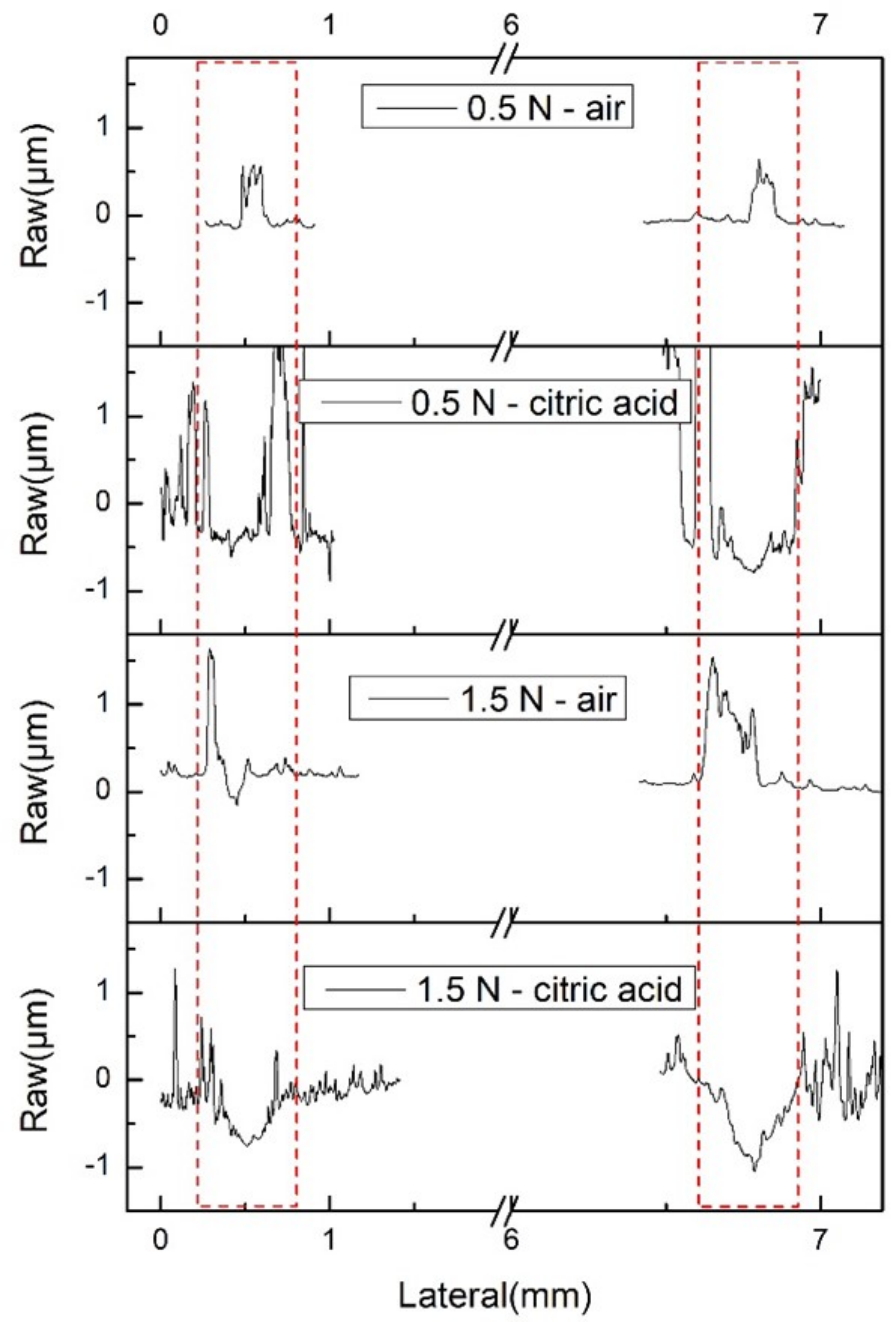

Figure 6 The wear track profile for samples tested in air and the citric acid $10^{-4} \mathrm{M}$ solution using normal loads of 0.5 and $1.5 \mathrm{~N}$. 

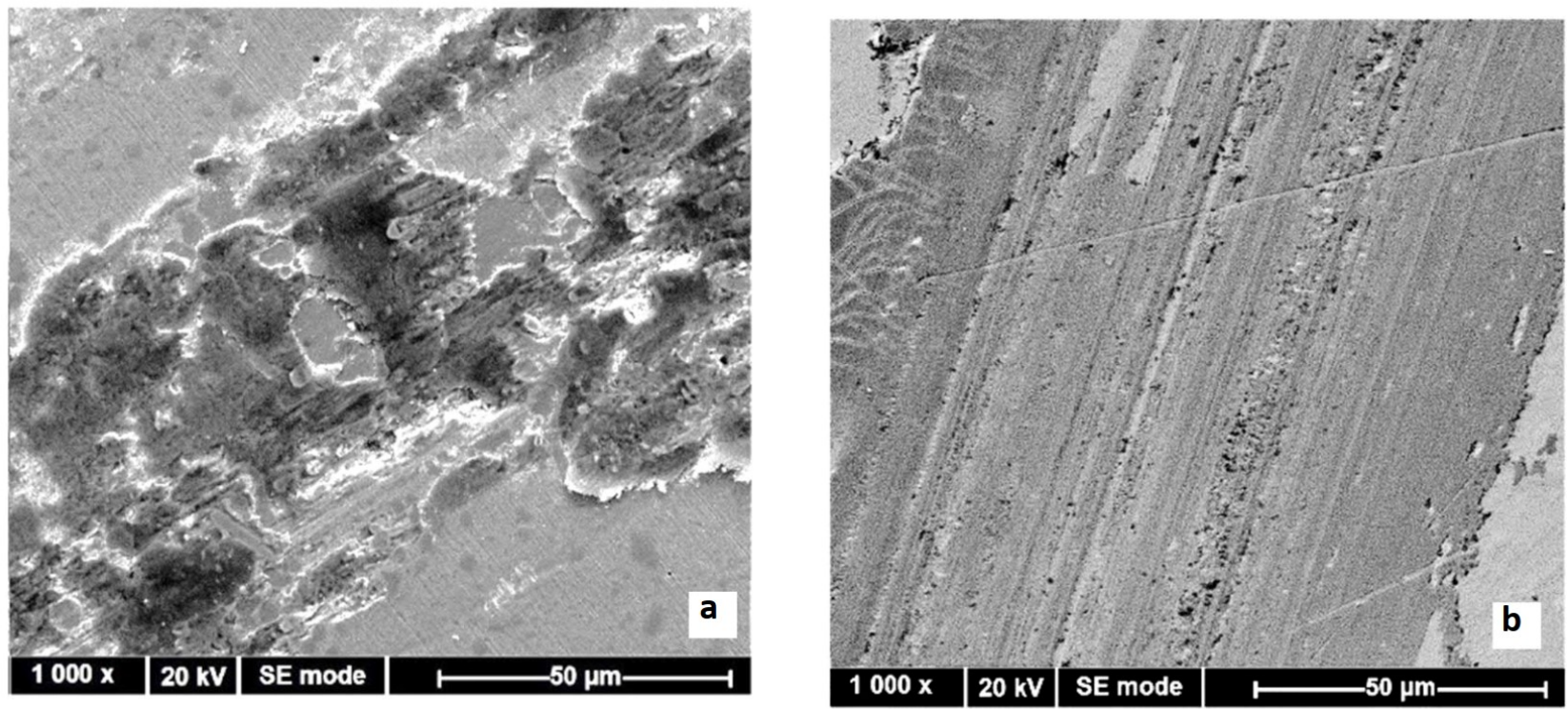

Figure 7 SEM image of the wear track after the pin on disc test at (a) $0.5 \mathrm{~N}$ and at (b) $1.5 \mathrm{~N}$ in air.
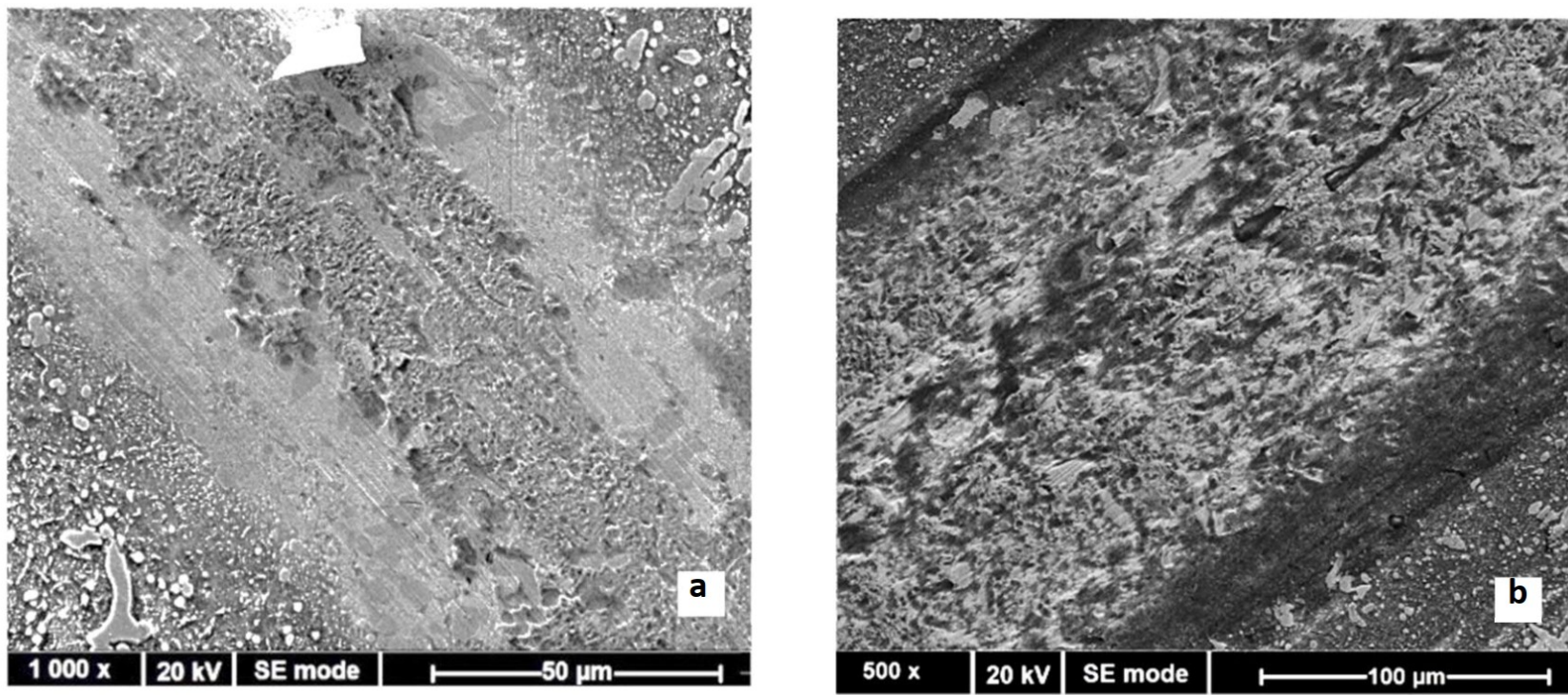

Figure 8 SEM image of the wear track after the pin on disc test at (a) $0.5 \mathrm{~N}$ at (b) $1.5 \mathrm{~N}$ in the citric acid $10^{-4} \mathrm{M}$ solution.

the polarization resistance of the material; the $\mathrm{C}$ element is a constant phase element (CPE) and describes a non-ideal capacitor when the capacitor phase angle is different from $90^{\circ}[13]$. CPEs are generally used to a describe surface reactivity, surface heterogeneity and roughness as well as the distributions of the current and potential caused by the electrode geometry and porosity [15]. The estimated value of $R_{p}$ was $3.3 \pm 0.01 \mathrm{k} \Omega \mathrm{cm}^{2}$, with a chi-square of 0.0052 suggesting a good fit. The estimated $i_{\text {corr }}$ was $9.3 \times 10^{-6} \pm 2 \times 10^{-8}$ $\mathrm{A} / \mathrm{cm}^{2}$, a value comparable to the one obtained by the Tafel extrapolation method. Our current densities are comparable to those obtained by other authors using different electrolytes $[12,16,17]$. Moreover, the obtained $R_{p}$ and $i_{\text {corr, }}$ by both methods, resembled a surface under corrosion, and hence the AISI D2 steel was corroded by the citric acid solution. This type of behavior has been reported for other values of acidity due to precipitation of the alloying elements [16-18]. Furthermore, precipitation of the alloying elements is commonly found in iron-alloys with the ce- mentite phase [19].

A comparison of the steel surface before and after the impedance test is shown in Figure 5. The image (a) of the polished surface shows a uniform surface where some polishing lines can be identified, and (b) shows a micrograph of the surface of the steel after being exposed to the citric acid solution. In Figure $5 b$ it is possible to see that accumulation of material has occurred in different parts of the surface, the lines due to the polishing are no longer visible, and the surface texture has been radically changed compared to the untreated steel.

\subsection{Wear and tribology}

The temporal evolution of the coefficient of friction (COF) was measured during the pin on discs tests at $0.5 \mathrm{~N}$ and $1.5 \mathrm{~N}$, in air and in contact with citric acid $10^{-4} \mathrm{M}$ solution. At the beginning of each test, the coefficient of friction increased sharply (running in), then after 10-30 minutes a 
steady value was achieved. The average coefficient of friction and its standard deviation were calculated in the steady range of the measurement, and for the $0.5 \mathrm{~N}$ tests was $0.68 \pm 0.09$ in air and $0.47 \pm 0.03$ in citric acid. Furthermore, at $1.5 \mathrm{~N}$ the COFs were $0.58 \pm 0.20$ in air, and 0.53 \pm 0.07 in the citric acid solution. These results show a diminution of the COF when the steel was in contact with the citric acid aqueous solution. This reduction of the COF can be attributed to lubrication by the citric acid solution, and such effects has been reported for other aqueous solutions [11].

Topographical graphs of the wear profile for each tested condition are displayed in Figure 6; the dotted lines indicate the area of the wear track on each side of the sample. A very similar amount and type of wear can be observed in the wear tracks on the respective left-hand and right-hand sides of each sample. The tests in air showed that there was accumulated material in the wear track and a smooth surface in the surrounding area. For the tests performed in the citric acid $10^{-4} \mathrm{M}$ solution the damage over the surface could be seen within the wear track and in the surrounding area. For the sample tested at $0.5 \mathrm{~N}$, the wear track was difficult to identify since the surrounding area showed little damage due to corrosion. While for $1.5 \mathrm{~N}$ test, the material loss was very evident with a maximum wear track depth of about $800 \mathrm{~nm}$. As a result of the pin on disc tests the surface roughness changed, and the average surface roughness of the areas close to the wear track were, respectively, for the 0.5 and $1.5 \mathrm{~N}$ loads, $245 \pm 200 \mathrm{~nm}$ and $238 \pm 370$ in air, and $720 \pm 60 \mathrm{~nm}$ and $773 \pm 90 \mu \mathrm{m}$ in citric acid.

With the help of the surface topographies after the pin on disc test, the loss volume was calculated. In air the total loss was $2.4 \times 10^{-5} \pm 1.8 \times 10^{-6} \mathrm{~mm}^{3}$ and $2.1 \times 10^{-4} \pm 4.2 \times 10^{-5} \mathrm{~mm}^{3}$, respectively, for the 0.5 and $1.5 \mathrm{~N}$ loads. Meanwhile, in citric acid the loss was $3.3 \times 10^{-3} \pm 1.6 \times 10^{-3} \mathrm{~mm}^{3}$ at $0.5 \mathrm{~N}$ and $2.3 \times 10^{-3} \pm 4.9 \times 10^{-4} \mathrm{~mm}^{3}$ at $1.5 \mathrm{~N}$. Such changes make evident that the damage over the steel surface is more significant in the presence of a corrosive environment. Considering the results of average roughness and loss volume it becomes evident that the corrosion process significantly increased the surface damage. Under dry conditions, the wear loss was an order magnitude larger at $1.5 \mathrm{~N}$ than at $0.5 \mathrm{~N}$. The difference was drastically diminished when the sample
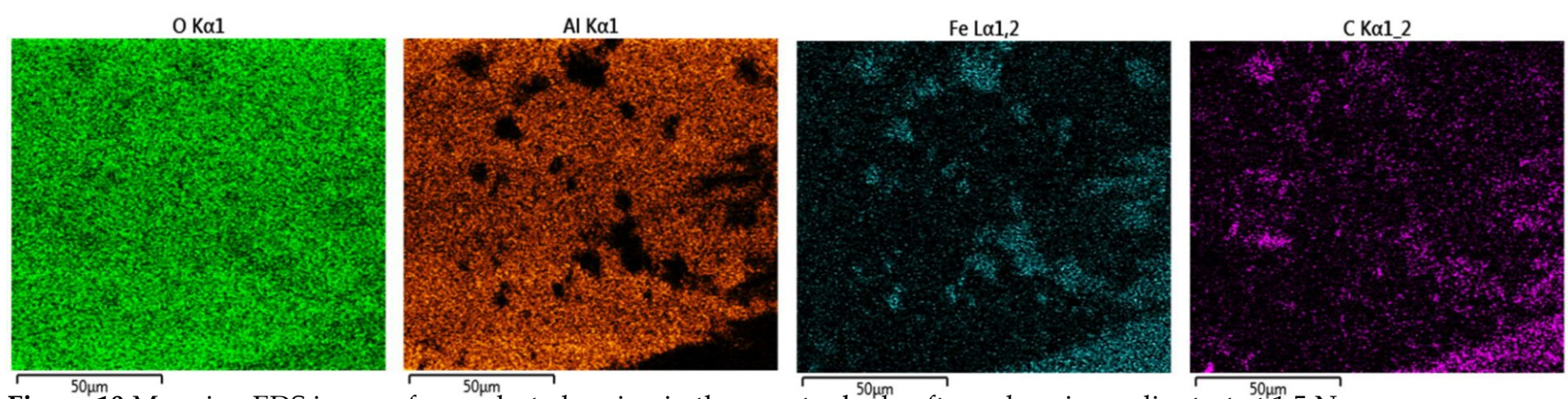

Figure 10 Mapping EDS images for a selected region in the counter body after a dry pin on disc test at $1.5 \mathrm{Nom}$
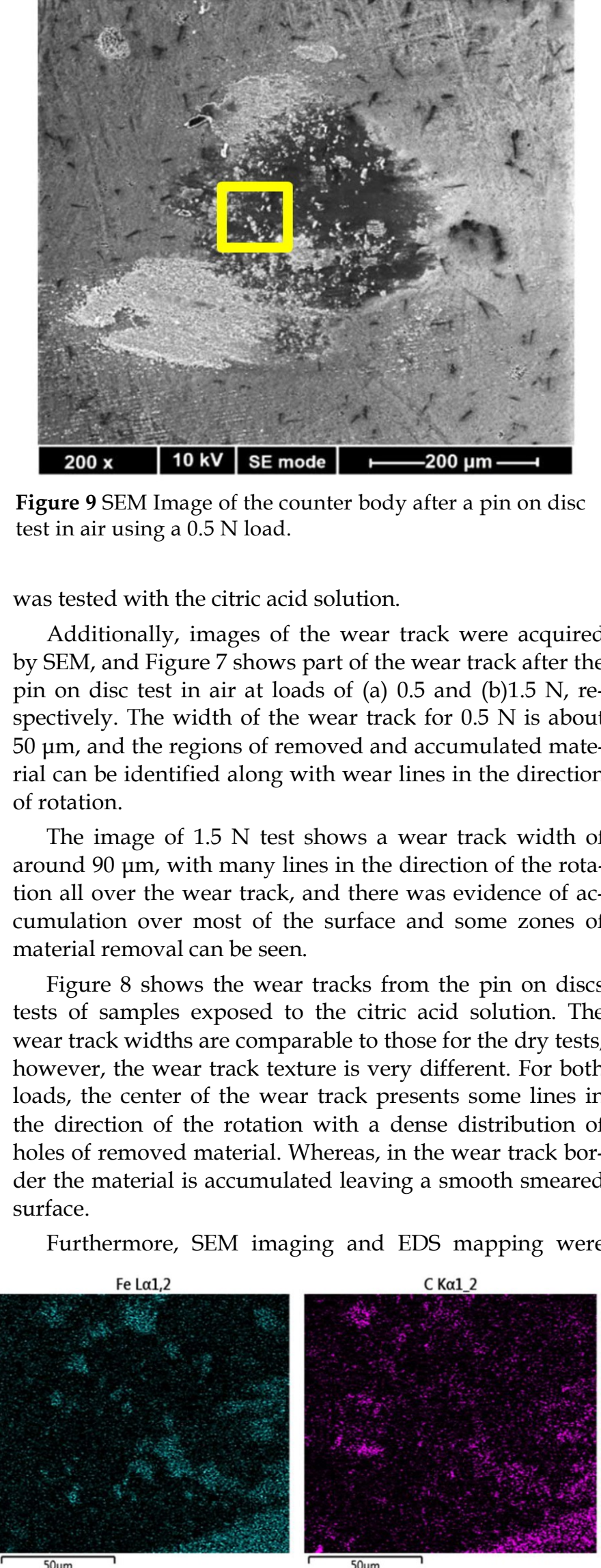

Figure 9 SEM Image of the counter body after a pin on disc test in air using a $0.5 \mathrm{~N}$ load.

was tested with the citric acid solution.

Additionally, images of the wear track were acquired by SEM, and Figure 7 shows part of the wear track after the pin on disc test in air at loads of (a) 0.5 and (b) $1.5 \mathrm{~N}$, respectively. The width of the wear track for $0.5 \mathrm{~N}$ is about $50 \mu \mathrm{m}$, and the regions of removed and accumulated material can be identified along with wear lines in the direction of rotation.

The image of $1.5 \mathrm{~N}$ test shows a wear track width of around $90 \mu \mathrm{m}$, with many lines in the direction of the rotation all over the wear track, and there was evidence of accumulation over most of the surface and some zones of material removal can be seen.

Figure 8 shows the wear tracks from the pin on discs tests of samples exposed to the citric acid solution. The wear track widths are comparable to those for the dry tests; however, the wear track texture is very different. For both loads, the center of the wear track presents some lines in the direction of the rotation with a dense distribution of holes of removed material. Whereas, in the wear track border the material is accumulated leaving a smooth smeared surface.

Furthermore, SEM imaging and EDS mapping were 
performed on the counter bodies. Figure 9 shows an example of the SEM image where damage at the contact point can be identified; the damage can be seen to be a small flattering of the surface and an evident change on the surface texture. The EDS test was performed within the region of the square in the Figure9. The elemental maps are shown in Figure 10, showing the distribution of $\mathrm{Al}, \mathrm{O}, \mathrm{C}$, and $\mathrm{Fe}$, and these elements had average concentrations of $41 \%$, $35 \%, 16 \%$ and $6 \%$, respectively.

The SEM images corroborated the existence of the stickslip motion since lines were found over the wear tracks, along with zones of both accumulation and removal of material. Furthermore, it was possible to identify the wear mechanism in the case of tribocorrosion; abrasive wear, and in this case, the abrasion occurred between the material adhered to the counter body and the sample surface. The presence and details of material on the counter body was corroborated by SEM and the EDX measurement, showed that $\mathrm{O}, \mathrm{Al} \mathrm{Cr}$ and $\mathrm{Fe}$ were present, i.e., a mix of the steel surface and the counter-body. The oxygen and aluminum were mainly from the counter body, whilst the iron and chromium were from the sample surface.

\section{Conclusion}

AISI D2 is a tool steel which has good mechanical properties and a high wear resistance, our pin on disc studies showed that this material had small volume losses under dry conditions. Such material loss occurred by abrasive wear as suggested by the material found in the counter body. The volume losses of about $10^{-5}$ and $10^{-4} \mathrm{~mm}^{3}$ at 0.5 and $1.5 \mathrm{~N}$ of normal load under the dry conditions, show unsurprisingly that the amount of volume loss increases with the load[20].

The corrosion resistance was poor when the material was exposed to acidic conditions and resulted in corrosion currents of approximately $10^{-6} \mathrm{~A} / \mathrm{cm}^{2}$. Such corrosion behavior effectively boosted the tribological damage, increasing the volume loss to values about $10^{-3} \mathrm{~mm}^{3}$, a value of at least one order of magnitude larger than those found for the dry tests. Hence corrosion and wear of AISI D2 steel show a positive synergism which badly affects the performance in contact with citric acid. In order to use AISI D2 steel tools under acidic $\mathrm{pH}$ conditions, surface protection through the use of appropriate thin film coatings is highly recommended.

\section{Acknowledgments}

The authors wish to acknowledge financial support by CONACyT through the grant 270930/439637, and the PAPIIT project IG101220. We thank Dr. E. Chevallier for his comments and feedback during the preparation of this paper.

\section{References}

[1] H. Paxton, Steel, Kirk-Othmer Encycl. Chem. Technol. (2004). https:// doi.org/10.1002/0471238961.1920050516012420.a01.p $\underline{\mathrm{ub} 2}$.

[2] J.R. Davis, ASM specialty handbook: tool materials, ASM international, 1995.

[3] L. Tang, C. Gao, J. Huang, H. Zhang, W. Chang, Dry sliding friction and wear behaviour of hardened AISI D2 tool steel with different hardness levels, Tribol. Int. 66 (2013) 165-173. https:/ / doi.org/10.1016/ j.triboint.2013.05.006.

[4] H.Y. Paine, Frank A., Paine, Packaging machinery, in: A Handb. Food Packag., Springer, Boston, MA, 1992. https://doi.org/http://10.1007/978-1-46152810-4.

[5] L. Shan, Y. Wang, Y. Zhang, Q. Zhang, Q. Xue, Tribocorrosion behaviors of PVD CrN coated stainless steel in seawater, Wear. 362-363 (2016) 97-104. https://doi.org/10.1016/j.wear.2016.05.016.

[6] K.L. Yam, Encyclopedia of Packaging Technology, Wiley, A John Wiley Sons, Inc. (2009). https:// doi.org/10.1017/S2042169900004284.

[7] A. Derossi, A.G. Fiore, T. de Pilli, C. Severini, A review on acidifying treatments for vegetable canned food, Crit. Rev. Food Sci. Nutr. 51 (2011) 955-964. https://doi.org/10.1080/10408398.2010.491163.

[8] FDA/Center for Food Safety \& Applied Nutrition, Approximate $\mathrm{pH}$ of Foods and Food Products, (2008) 1-13. http:/ / www.foodscience.caes.uga.edu/ extension/documents/fdaapproximatephoffoodslacf -phs.pdf.

[9] P. Taylor, Canned Food A Review on Acidifying Treatments, (2011) 37-41. https:// doi.org/10.1080/10408398.2010.491163.

[10] Y. Shan, Chapter Three - Machinery and Equipment for Canned Citrus Product Processing, (2016) 47-104 https://doi.org/10.1016/B978-0-12-804701-9.00003$\underline{4}$.

[11] M.S. Karakaş, Tribocorrosion behavior of surfacemodified AISI D2 steel, Surf. Coatings Technol. 394 (2020) 125884. https:// doi.org/10.1016/ j.surfcoat.2020.125884.

[12] V. Sista, O. Kahvecioglu, O.L. Eryilmaz, A. Erdemir, S. Timur, Electrochemical boriding and characterization of AISI D2 tool steel, Thin Solid Films. 520 (2011) 1582-1588. https:/ / doi.org/10.1016/ j.tsf.2011.07.057

[13] G.W. Walter, A review of impedance plot methods used for corrosion performance analysis of painted metals, Corros. Sci. 26 (1986) 681-703. https:// doi.org/10.1016/0010-938X(86)90033-8.

[14] T.M. Manhabosco, S.M. Tamborim, C.B. dos Santos, I.L. Müller, Tribological, electrochemical and triboelectrochemical characterization of bare and nitrided 
Ti6Al4V in simulated body fluid solution, Corros. Sci. 53 (2011) 1786-1793. https:/ / doi.org/10.1016/ j.corsci.2011.01.057.

[15] M.F. Montemor, M.G.S. Ferreira, Electrochemical study of modified bis-[triethoxysilylpropyl] tetrasulfide silane films applied on the AZ31 Mg alloy, Electrochim. Acta. 52 (2007) 7486-7495. https:// doi.org/10.1016/i.electacta.2006.12.086.

[16] B.F. Chen, W.L. Pan, G.P. Yu, J. Hwang, J.H. Huang, On the corrosion behavior of TiN-coated AISI D2 steel, Surf. Coatings Technol. 111 (1999) 16-21. https://doi.org/10.1016/S0257-8972(98)00710-5.

[17] J.C. Díaz-Guillén, J.A. Díaz-Guillén, E.E. GrandaGutiérrez, M.R. Díaz-Guillén, M.A. GonzálezAlbarrán, Electrochemical corrosion performance of AISI D2 tool steel surface hardened by pulsed plasma nitriding, Int. J. Electrochem. Sci. 8 (2013) 973982.

[18] F.E. Castillejo, D.M. Marulanda, J.J. Olaya, J.E. Alfonso, Wear and corrosion resistance of niobiumchromium carbide coatings on AISI D2 produced through TRD, Surf. Coatings Technol. 254 (2014) 104 -111. https://doi.org/10.1016/j.surfcoat.2014.05.069.

[19] W. Beitz, K.-H. Kuttner, Handbook of Mechanical Engineering, Springer - Verlag, 1994. https:// doi.org/10.1007/978-1-4471-3566-1.

[20] J.F. Achard, Contact and rubbing of flat surface, J. Appl. Phys. 24 (1953) 981-988. https:// doi.org/ https://doi.org/10.1063/1.1721448. 